\title{
COMPARATIVE STUDY OF NITROSAMINE IN ROASTED FOOD BASE ON THE ROASTING METHODS
}

\author{
O. T. Ogunmodede ${ }^{1, *}$, A. A. Ojo ${ }^{1}$, O.Jegede $^{2}$ \\ ${ }^{1}$ Chemical Sciences Department, Afe Babalola University, Ado-Ekiti, Ekiti State, Nigeria \\ ${ }^{2}$ Department of Chemistry, College of Education, Ikere Ekiti, Nigeria \\ *E-mail address: taiwokehindelolade@gmail.com
}

Keywords: Roasted food, Nitrosamine, Roasting, Toxicants.

\begin{abstract}
The present study examined the interrelationships of roasting methods and nitrosamine compounds (NA) content in eleven food sample investigated. The total level of NA in examined food ranged from $1.1 \times 10^{-3} \mu \mathrm{g}$ per $\mathrm{g}$ in oven roasted white maize to $5.0 \times 10^{-3} \mu \mathrm{g}$ per $\mathrm{g}$ in wood roasted pig meat that is lower than the legal level in WHO $(0.001 \mu \mathrm{g}$ per $\mathrm{kg})$. The significant increase of NA concentration in all food samples on roasting was observed. Methods of roasting have significant effects on the level of nitrosamine in each of the material used.
\end{abstract}

\section{INTRODUCTION}

Nitrosamines are a class of chemical compounds with the generic chemical structure $\mathrm{R}_{2} \mathrm{NN}=\mathrm{O}$. They are produced under certain conditions (acidic $\mathrm{pH}$, high temperature, presence of certain reducing agents) in a variety of media (products, biological systems, air, etc) when nitrites react with the so called nitrosatable substances, mainly secondary amines. They are found in tanneries and plants manufacturing pesticides, rubber products and tires as well as fish processing plants, foundries, dye-making plants and research labs[1].

Nitrosamine occur commonly because their chemical precursors-amine and nitrosating agents occur commonly and the chemical reaction for nitrosamine formation is quite facile [2]. The carcinogenic properties of $\mathrm{N}$-nitrosodimethylamine were established and consequently it is important to ensure that the concentration present in food is below a level which is hazardous to man. Nitrosamines are believed to be formed due to the interaction of various nitrosating agents (e.g. nitrite, nitrogen oxide) and amines in the foods [3]. Nitrosamine is found in many food stuffs especially beer [4], fish by products and in meat and cheese products preserved with nitrite picking salts. Their existence has been confirmed in food products, cosmetic product, tobacco smoke [5] soil, ground water [6]. Most N- nitrosamines like N-methylaniline and dimethylaniline have been shown to be carcinogenic in laboratory animals [7]. The N-nitroso compounds are known to be acutely toxic, mutagenic, teratogenic and carcinogenic. No animal species is known to be resistant to the carcinogenicity effect of nitrosamines and other N-nitroso compounds [8]. Naturally Nnitrosamines could be found as a result of biological, chemical or photochemical processes [9]. This study is therefore aimed at comparing the effects of roasting methods on the level of nitrosamines in some roasted food materials.

\section{MATERIALS AND METHODS}

Samples food materials fish(Tilapia), cashew nut(Anacardium occidentale), white yam(Discorea rotunda),plantain(Musa sapientum), groundnut(Arachis hypogaea), cocoyam(Colocasia esculenta), bush meat, beef meat, pig meat, coconut(Cocos nucifera), white maize(Zea may), yellow maize(Zea may) were purchased from Ado-Ekiti in Nigeria.

\section{Methods of Roasting}

Coal Method: Each sample was roasted by using coal smoking method. Direct smoking method was used at $160^{\circ} \mathrm{C}$, and the moisture level was controlled. Each roasted sample materials were 
homogenized well with blender and stored in a refrigerator at $4^{0} \mathrm{C}$. The analysis was done within a limited time.

Oven Method: Each sample was roasted by using oven roasting method. Samples were placed in the oven at $160^{\circ} \mathrm{C}$, and the moisture level was controlled. Each roasted sample materials were homogenized well with blender and stored in a refrigerator at $4^{0} \mathrm{C}$. The analysis was done within a limited time.

Wood Smoking Method: Each sample was roasted by using wood smoking method. Samples were placed directly on wire gauze on a burning wood at $160^{\circ} \mathrm{C}$, and the moisture level was controlled. Each roasted sample materials were homogenized well with blender and stored in a refrigerator at $4^{0} \mathrm{C}$. The analysis was done within a limited time.

Standard calibration curve: For the standard calibration graph 1, 2, 3, 4 and $5 \mathrm{~cm}^{3}$ sodium nitrate working solution (corresponding to $0.2,0.4,0.6$ and $1.0 \mu \mathrm{g} \mathrm{NaNO}_{3}$ ) were added to $50 \mathrm{~cm}^{3}$ volumetric flasks. To each flask was added $1 \mathrm{~cm}^{3} \mathrm{~N}-1$ naphthyl reagents. Each flask was made up to $50 \mathrm{~cm}^{3}$ with distilled water. After standing for $25 \mathrm{~min}$, absorbance at $540 \mathrm{~nm}$ was measured. Absorbance at $540 \mathrm{~nm}$ was plotted against concentration in $\mu \mathrm{gcm}^{3}$ to obtain the calibration graph.

Determination of nitrosamine: Ammonium sulphamate was added to $10 \mathrm{~g}$ of the roasted food samples to stabilizer any N-nitrosamine and also as a free nitrite scavenger. An aqueous sodium chloride solution was then added to liberate the nitrosamine from the nitrosamine-water emulsion. The aqueous mixture was quantitatively transferred to a separating funnel where it was extracted with pentane to remove any non polar components. The aqueous phase was extracted with ethyl acetate and the organic phase was washed with water and then dried with $\left(\mathrm{Na}_{2} \mathrm{SO}_{4}\right)$. The solvent was concentrated in vacuo using a rotary evaporator. The residue was dissolved in glacial acetic acid and an aliquot of denitrosation reagent (3\% v/v) $\mathrm{HBr}$ in glacial acetic acid) was added. Sulphanilamide was mixed with the test aliquot and the $\mathrm{N}$ - naphythyl reagent was added. The absorbance of the test sample was measured at 540nm using spectrophotometer 20 [10]

\section{Data Evaluation}

The total N-nitroso content express as

$$
=\frac{\mu \mathrm{g} \cdot \mathrm{cm}^{-3} \mathrm{NaNO}_{3}}{\text { Mass of sample }} \times \frac{1 \text { rom standard graph }}{0.5} \times\left\{\begin{array}{lll}
\underline{30} & \times & \underline{100} \\
69 & 22.4
\end{array}\right\} \mu \mathrm{g} / \mathrm{g}
$$

Where the portion of the equation between the vertical lines is the conversion factor from $\mathrm{NaNO}_{3}$ to nitrosamine.

\section{STATISTICAL ANALYSIS}

The analytical data are reported as mean \pm standard deviation of triplicate independent measurements and were subjected to ANOVA, the significance of mean differences was determined by Duncans posthoc test and t-test using SPSS version 14.0.

\section{RESULTS AND DISCUSSION}

Table 1. Total N-nitroso content $(\mu \mathrm{g} / \mathrm{g})$ in raw, oven roasted, wood roasted and coal roasted food material.

\begin{tabular}{lllll}
\hline \multicolumn{5}{c}{$\begin{array}{c}\text { N-nitroso content } \\
(\mu \mathrm{g} / \mathrm{g}) \times 10^{-3}\end{array}$} \\
\hline Sample & Raw sample & Oven roasted & Wood roasted & Coal roasted \\
\hline White yam & $2.8 \pm 0.03$ & $2.8 \pm 0.01$ & $3.5 \pm 0.02$ & $3.3 \pm 0.01$ \\
\hline Groundnut & $1.1 \pm 0.01$ & $1.2 \pm 0.01$ & $2.0 \pm 0.01$ & $1.9 \pm 0.03$ \\
\hline Cocoyam & $1.2 \pm 0.03$ & $1.4 \pm 0.01$ & $2.9 \pm 0.01$ & $2.4 \pm 0.01$ \\
\hline Yellow maize & $1.3 \pm 0.01$ & $1.7 \pm 0.02$ & $2.8 \pm 0.02$ & $2.7 \pm 0.01$ \\
\hline White maize & $0.2 \pm 0.01$ & $1.1 \pm 0.01$ & $1.9 \pm 0.01$ & $1.6 \pm 0.02$ \\
\hline Cashew nut & $1.8 \pm 0.01$ & $3.7 \pm 0.03$ & $4.0 \pm 0.02$ & $3.4 \pm 0.01$ \\
\hline
\end{tabular}




\begin{tabular}{lllll}
\hline Coconut & $0.7 \pm 0.03$ & $1.2 \pm 0.01$ & $2.3 \pm 0.02$ & $2.0 \pm 0.01$ \\
\hline Plantain & $1.3 \pm 0.01$ & $1.7 \pm 0.01$ & $2.7 \pm 0.01$ & $2.2 \pm 0.02$ \\
\hline Fish & $2.8 \pm 0.01$ & $3.7 \pm 0.03$ & $4.7 \pm 0.03$ & $4.1 \pm 0.01$ \\
\hline Bush meat & $1.8 \pm 0.03$ & $2.3 \pm 0.01$ & $2.0 \pm 0.01$ & $2.9 \pm 0.01$ \\
\hline Cow meat & $2.0 \pm 0.01$ & $3.0 \pm 0.01$ & $3.9 \pm 0.02$ & $3.7 \pm 0.02$ \\
\hline Pig meat & $3.1 \pm 0.02$ & $3.4 \pm 0.02$ & $5.0 \pm 0.01$ & $4.3 \pm 0.01$ \\
\hline
\end{tabular}

Table 1 shows the nitrosamine levels in the raw and roasted food materials. The nitrosamine levels varied from $1.1 \times 10^{-3}(\mu \mathrm{g} / \mathrm{g})$ in white maize to $3.7 \times 10^{-3}(\mu \mathrm{g} / \mathrm{g})$ in fish in oven roasted food sample which was higher than the nitrosamine level in raw food samples. Nitrosamine levels in wood roasted food samples varied from $1.9 \times 10^{-3}(\mu \mathrm{g} / \mathrm{g})$ in white maize to $5.0 \times 10^{-3}(\mu \mathrm{g} / \mathrm{g})$ in pig meat, while nitrosamine levels in coal roasted food sample varied from $1.6 \times 10^{-3}(\mu \mathrm{g} / \mathrm{g})$ in white maize to $4.3 \times 10^{-3}(\mu \mathrm{g} / \mathrm{g})$ in pig meat. These values were here than the level in raw food samples. These were at the American Food and Drug Administration (FDA) action level. Higher levels may result from microbial reduction of nitrate stored under in appropriate conditions [11]. While roasting process increased the nitrosamine levels in all the samples as shown in table I. Similar changes in levels of nitrosamine in food after cooking were observed for vegetables by Ezeagu and Fafunso [12]. The apparent difference in the nitrosamine contents between the raw and roasted food sample might be due to reconstitution and chemical interactions between the various component effect by heating or boiling during processing [13].

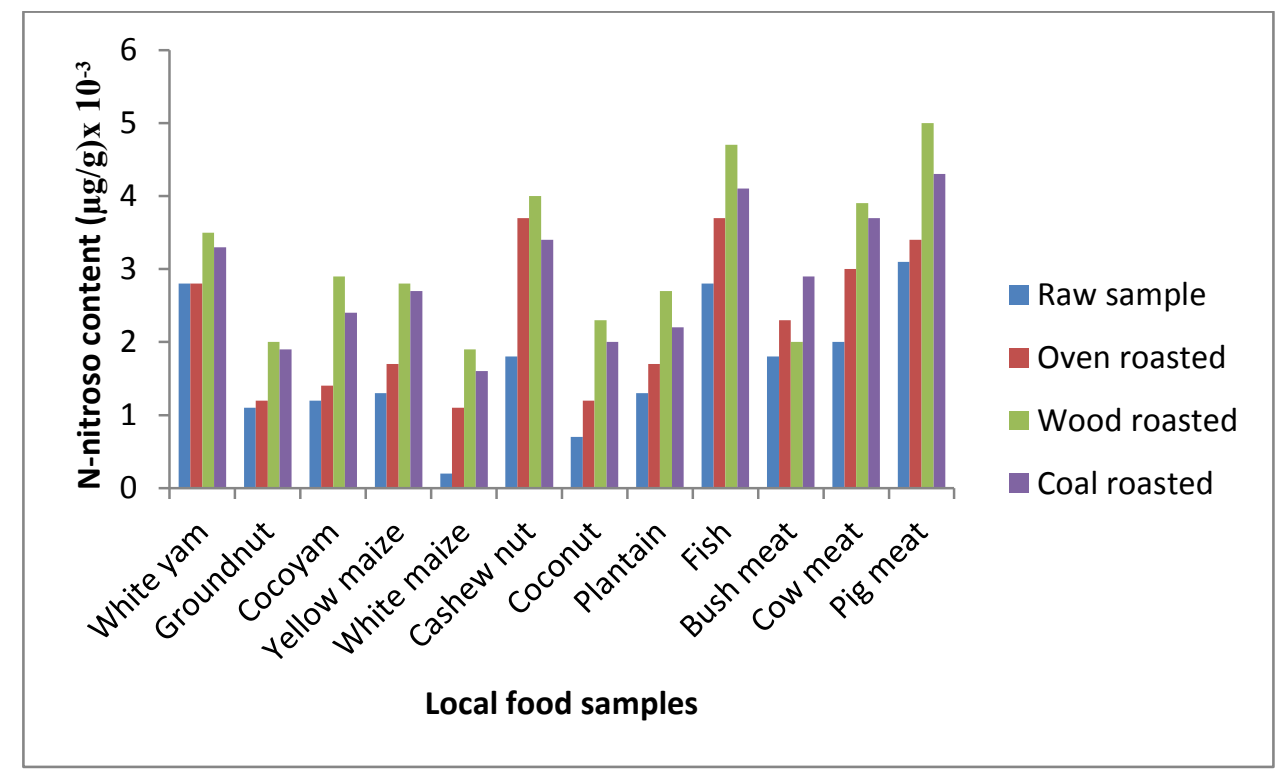

Fig.1. The variation in the level of nitrosamine in roasted food sample with respect to roasting methods.

The results suggested that the use of wood, coal and oven roasting method may cause some small increase in the natural nitrosamine level. The size of this increase is markedly affected by the roasting procedure viz: the increase when fish is roasted in oven or coal or wood is greater than raw; similarly placing every other food samples, the level in wood roasting nitrosamine levels is greater than coal, and oven. The differences between the levels in food samples of different species on different occasion were at least great as these attributed to roasting. Earlier work of Kawabata et al [14] reported that coal of Japanese dried fish results in significantly higher levels of nitrate, nitrite and nitrosamine (up to 300ppm). Various conditions can affect nitrosamines formation, for example spices such as pepper can be a source of formation.

\section{Conclusion}

The study revealed that a significant relationship exist between nitrosamine value of coal, wood and oven roasting methods. The gases produced during wood roasting contributed to high 
value of nitrosamine wood roasted food materials than the coal and oven roasted. Based on the findings the use of direct roasting (smoking) using wood, coal of food materials should be discouraged and that processing of the food materials be modified to reduce the presence of toxicants.

\section{REFERENCES}

[1]. Fishbein L. Overview of some aspects of occurrence, formation and analysis of nitrosamines. Sci Total Environ. 1979;13 (2):157-88.

[2] Scanlan, R. A., \& Ryes, F. G. (1985): An update of analytical techniques for N-nitrosamines. Food Technology, 30, 95-99.

[3] Khodadady M, Shahryari T, Dorri H, Sharifzadah GR, Ziyazade A,. Evaluation of nitrite in meat products (sausages and salami) are distributed in Birjand in 2012 European Journal of Experimental Biology, 2012, 2 (6):2120-2124.

[4] Serag H, Edrees G, Effect of chitosan-Cu complex on biological disturbance induced by dibutylnitrozamine (DBNA)European Journal of Experimental Biology, 2011, 1(4):87-92

[5] Lee HL, Wang S, Lin DP, Hsieh H, (2007): 4-(Methylnitrosamino)-1-(3-pyridyl)-1-butanone (NNK) metabolism-related enzymes gene polymorphisms, NNK metabolites levels and urothelial carcinoma. Talanta, 73: 76.

[6] Pan X B, Zhang SB, Cox TA, Anderson, Cobb GP, (2006), Determination of N-nitroso derivatives of hexahydro-1,3,5-trinitro-1,3,5-triazine (RDX) in soils by pressurized liquid extraction and liquid chromatography-electrospray ionization mass spectrometry. J. Chromatogr.A. 1107(1-2): $2-8$.

[7] Preussmann R, Stewart BW (1984): N-Nitroso carcinogens. In: Searle CE (ed) Chemical carcinogens. ACS Monograph 182, American Chemical Society, Washington, DC, p 643.

[8] Hildesheim A, Dosemeci M, Chan CC, Chen CJ, Cheng YJ, Hsu MM, Chen IH, Mittl BF, Sun B, Levine PH, Chen JY, Brinton LA, Yang CS, (2001): Occupational exposure to wood, formaldehyde, and solvents and risk of nasopharyngeal carcinoma. Cancer Epid. Biomarkers Prev. $10,1145-1153$.

[9] Ayanaba A. Alexander M, (1974): Occurrence and Formation of Nitrosamines in Drinking Water Distribution Systems Focus Categories: Water Quality, Toxic Substances, Water Supply, and Nitrate Contamination. Journal Environmental quality. 3, 83-89.

[10] Telling G.M and Dunneth. P.C. (1981): Determination of U-nitrosodrethanolamine (NDELA) at race levels in shampoos and skin cream by a sample rapid calorimetric method. Int. Journal cosmetic. Science. 3, 241

[11] Ezeagu I.E; Ibe B.C. J. Coll. Med., 2004, 9, 45-47

[12] Ezeagu I.E; Fafunso M.A. (1995): Effect of Wilting and Processing on the Nitrate and Nitrite Contents of Some Nigerian Leaf Vegetables. Nurt. Health,10, 269-275

[13] Amoo, I.A., 1998. Estimation of crude proteins in some Nigerian foods. J. Applied Sci., 1: 6572.

[14] Kawabata T, Uibu J, Ohshima H, Matsui M, Hamano M, Tokiwa H. (1980). Occurence, formation and precursors of N-nitroso compounds in the japanese diet. IARC Sci Publ 31: 481-488 